\title{
NOVUM TESTAMENTUM
}

\section{GRAECE}

AD ANTIQUISSIMOS TESTES DENUO RECENSUIT

APPARATUM CRITICUM APPOSUIT

\section{CONSTANTINUS TISCHENDORF}

EDITIO OCTAVA CRITICA MAIOR

VOLUMEN III

\section{PROLEGOMENA}

SCRIPSIT

CASPARUS RENATUS GREGORY

ADDITIS CURIS + EZRAE ABBOT

PARS ALTERA

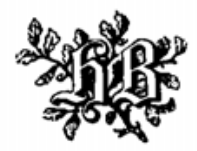

LIPSIAE

J. C. HINRICHS

1890 